\title{
Medidas Objetivas e Composição Tecidual da Carcaça de Cordeiros Alimentados com Diferentes Níveis de Energia em Creep Feeding 1
}

\section{Cledson Augusto Garcia ${ }^{2}$, Alda Lúcia Gomes Monteiro ${ }^{3}$, Ciniro Costa ${ }^{4}$, Marcela Abbado Neres ${ }^{5}$, Guilherme Jordão Magalhães Rosa ${ }^{6}$}

\begin{abstract}
RESUMO - O trabalho foi desenvolvido no Setor de Ovinocultura da Universidade de Marília, SP, objetivando avaliar o efeito dos três níveis de energia (2,6; 2,8 e 3,0 Mcal EM/kg MS) sobre as medidas objetivas das carcaças e do lombo, pesos e rendimentos dos cortes, além da composição tecidual e musculosidade da carcaça de cordeiros alimentados em creep feeding. As rações foram isoprotéicas (18,50\% PB), fornecidas ad libitum, duas vezes ao dia. Os cordeiros permaneceram com as ovelhas até o abate, quando atingiam o peso preestabelecido de $31 \mathrm{~kg}$. Posteriormente, os animais foram submetidos a jejum alimentar, registrando-se o peso vivo ao abate. Durante o resfriamento na câmara de refrigeração a $5^{\circ} \mathrm{C}$, por 24 horas, as carcaças foram penduradas pelas articulações tarso metartasiana, distanciadas em $17 \mathrm{~cm}$; sendo em seguida mensuradas. As carcaças foram seccionadas ao meio e a metade esquerda dividida em sete regiões anatômicas (paleta, perna, lombo, costelas falsas, costelas verdadeiras, baixo e pescoço), possibilitando o cálculo dos pesos e rendimentos dos cortes. Posteriormente, efetuou-se as mensurações no músculo Longissimus dorsi e a perna esquerda foi dissecada e determinados os pesos dos músculos, da gordura e dos ossos, além de calculado o índice de musculosidade. Os resultados revelaram diferenças significativas para as medidas de profundidade do tórax, peso e rendimento das costelas verdadeiras e gordura intermuscular da perna, sendo que o nível de 3,0 Mcal EM na ração proporcionou os melhores resultados, para cordeiros Suffolk alimentados e terminados em creepfeeding.
\end{abstract}

Palavras-chave: cortes, ovinos, Suffolk, musculosidade

\section{Objective Measurements and Tissue Composition of Carcass of Lambs Fed with Different Energy Levels in Creep Feeding}

\begin{abstract}
The experiment was carried out at Sheep Production Department, Universidade de Marília-SP, to evaluate the effect of energy levels (2.6, 2.8 and 3.0 Mcal ME/kg DM) on objective measures of carcasses and loin, cuts weight and yield and tissue composition and muscularity of carcasses of lambs under creep feeding. Isoprotein rations $(18.50 \% \mathrm{CP})$ were fed ad libitum, twice a day. Lambs stayed with their dams until slaughter weight ( $31 \mathrm{~kg}$ ). After, lambs were fasted, when slaughter live weight was recoded. During cooling at $5^{\circ} \mathrm{C}$ by $24 \mathrm{~h}$, carcasses were hanged by tarse-metartase articulation, distanced by $17 \mathrm{~cm}$, and, then, were measured. Later, carcasses were sectioned and the left side was divided in seven anatomical parts (shoulder, leg, loin, true ribs, false ribs, breast point and neck) to calculate weight and yield of cuts. Then, muscle Longissimus dorsi was evaluated. Left leg was dissected and it was considered muscle, fat and bone weights. Muscularity index was figured out. Results showed significant differences for thorax depth, true ribs weight and yield, and leg intermuscular fat. It was concluded that ration with 3.0 Mcal ME favored better results for Suffolk lambs fed and finished in creep feeding.
\end{abstract}

Key Words: cuts, muscularity, sheep, Suffolk

\section{Introdução}

No Brasil a carne ovina tem tido seu consumo aumentado, sendo o peso de abate e a qualidade da carcaça temas de discussão no momento, objetivando atender a demanda do mercado consumidor (Barros \& Simplício, 2001). Os pesos de abate e da carcaça devem ser correlacionados, pois interferem na com- posição tecidual da carcaça, daí a necessidade de pesquisas nessa área, inclusive estudos econômicos (Siqueira et al., 2001).

Dentre os sistemas intensivos de ovinos, Macedo (1995) destacou a suplementação concentrada em creep feeding, como forma de aumentar o peso ao desmame. Sañudo et al. (1988), estudando diferentes sistemas intensivos de produção de ovinos, concluí-

\footnotetext{
${ }_{1}^{1}$ Parte da Tese de Doutorado do primeiro autor, projeto financiado pela Universidade de Marília (UNIMAR) e FAPESP (98/07014-5)

2 Professor de Ovinocultura da FCA-UNIMAR, CP.504, CEP: 17.525-902, Marília-SP. E.mail: cgarcia-ca@unimar.br

3 Professora da UFPR, Departamento de Zootecnia, Curitiba-PR. E.mail: alda.Igm@ufpr.br

4 Professor do Departamento de Melhoramento e Nutrição Animal , FMVZ-UNESP, Campus de Botucatu-SP. E.mail: ciniro@fca.unesp.br ${ }^{5}$ Professora do CCA, UNIOESTE, Mal. Cândido Rondon, PR. E.mail: abbado@unioeste.br

${ }^{6}$ Professor do Departamento de Bioestatística - IB/ UNESP - Botucatu- SP.
} 
ram que os cordeiros não desmamados, recebendo dieta no creep feeding até o abate, apresentaram superioridade para a qualidade da carne, embora tenham apresentado maior quantidade de gordura de cobertura, principalmente as fêmeas.

Nos sistemas de produção de ovinos, o abate de animais precoces tem despertado o interêsse dos criadores. Garcia et al. (2001) e Neres et al. (2001 a,b) abateram cordeiros Suffolk em creep feeding, com peso entre 28 a $30 \mathrm{~kg}$, com idade ao redor de 60 a 80 dias, observando valores desejáveis para o rendimento das carcaças e dos cortes comerciais.

O estudo das carcaças tem como finalidade avaliar parâmetros subjetivos e objetivos, os quais estão relacionados com aspectos qualitativos e quantitativos das mesmas. As medidas da carcaça, quando combinadas com o peso, são preditores satisfatórios de sua composição em gordura, músculo e osso (El Karin et al., 1988).

O conhecimento dos pesos e rendimentos dos principais cortes da carcaça permite interpretação do desempenho animal (Macedo, 1998). Os únicos cortes padronizados na maior parte das regiões criatórias de ovinos são a paleta e a perna, porém para os demais cortes ocorrem variação, em função dos costumes regionais (Garcia, 1998).

Entre os cortes, a perna é considerada o mais nobre das carcaças ovinas, por encontrar-se nela o maior acúmulo de massas musculares (Monteiro et al., 1999). Assim, a composição tecidual da mesma é característica de grande importância, para a avaliação da qualidade da carcaça (Monteiro et al., 2000).

O peso da carcaça é parâmetro de grande importância no ponto vista comercial, pois quando esta tem peso elevado, verifica-se alteração em sua composição tecidual (Siqueira et al., 2001). Segundo Ruiz de Huidobro \& Cañeque (1994), o valor intrínseco dos animais está fundamentalmente determinado pela composição tecidual, pelo rendimento das partes e pela composição química da carcaça. Esses autores destacaram a importância das relações músculo:osso e da gordura subcutânea:gordura intermuscular, na determinação da qualidade do produto.

Purchas et al. (1991) indicaram que a relação músculo:osso é uma medida objetiva frequentemente associada à maior deposição de massa muscular, porém muitas vezes, essa relação apresentando-se alta, pode ser reflexo de ossos mais leves e não necessariamente de músculos mais pesados. Assim, faz-se necessário considerar dois parâmetros, rela- ção músculo:osso e índice de musculosidade, separadamente.

Segundo Silva Sobrinho (1999), a musculosidade da carcaça foi definida por De Boer et al. (1974) como a espessura do músculo relativa às dimensões do esqueleto animal, e a conformação, como a espessura de músculo e gordura relativa às dimensões do esqueleto. No entanto, apesar da existência dessas definições claras, medidas objetivas de musculosidade não têm sido muito usadas, devido às dificuldades em se medir a profundidade dos músculos. O mesmo autor cita Kirton et al. (1983) afirmando que carcaças bem musculadas, de acordo com a observação visual, foram associadas com alta relação músculo:osso, mas também elevada proporção de gordura:músculo.

Dessa forma, Purchas et al. (1991) propuseram uma medida objetiva de musculosidade, que avalia a relação entre a profundidade média dos músculos, através de um grupo de músculos que circundam um determinado osso, relativa ao comprimento do mesmo.

O trabalho foi conduzido com o objetivo de avaliar diferentes níveis de energia na ração sobre as medidas objetivas das carcaças e do músculo Longissimus dorsi, os pesos e rendimentos dos cortes, além da composição tecidual e musculosidade da carcaça de cordeiros Suffolk alimentados e terminados em creep feeding.

\section{Material e Métodos}

O experimento foi realizado no Setor de Ovinocultura da Fazenda Experimental "Marcelo Mesquita Serva", pertencente à Faculdade de Ciências Agrárias da Universidade de Marília (UNIMAR), no município de Marília, SP. O delineamento experimental foi inteiramente casualizado com três tratamentos (2,6;2,8 e 3,0 Mcal EM/kg MS da ração) e doze repetições. Foram utilizados 36 cordeiros inteiros, mestiços Suffolk, oriundos de parto simples e alimentados em creep feeding, com rações isoprotéicas $(18,50 \%$ PB), fornecidas ad libitum, duas vezes ao dia.

No terço final de gestação e durante todo o período experimental, as ovelhas foram suplementadas diariamente com feno de Tifton-85 (Cynodon spp.) à vontade, além de concentrado (16,17\% PB e 77\% NDT), numa área exclusiva para as mesmas, constituída de grão de milho moído, farelo de trigo e farelo de soja, fornecendo $1 \%$ do peso vivo, com base na matéria seca, visando atender as exigências nutricionais dessa fase (NRC, 1985).

Após o parto, as ovelhas foram distribuídas alea- 
toriamente, com seus respectivos cordeiros, em piquetes de estrela branca (Cynodon plectostachyus). Em virtude da concentração de parições no período do inverno, quando a pastagem apresentava pequena disponibilidade de matéria seca e baixa qualidade, os lotes foram submetidos em sistema de pastejo alternado.

Logo após o nascimento, os cordeiros foram pesados e numerados. Na primeira semana de vida, os mesmos foram fechados na área cercada do creep feeding por 4 horas diárias, para adaptação às instalações e para o contato inicial com o alimento sólido, com acesso à ração ad libitum.

Aos 14 dias de idade, os cordeiros receberam a $1^{\mathrm{a}}$ dose de vacina contra clostridioses (Polivalente Sintoxan $\left.{ }^{\circledR}\right)$, com reforço após 30 dias. Semanalmente foi realizada a coleta de fezes, diretamente da ampola retal dos cordeiros e ovelhas, objetivando o monitoramento das infecções parasitárias, através da contagem do número de ovos por grama de fezes (OPG), segundo metodologia de Matos \& Matos (1988). A desverminação é recomendada toda vez que a contagem média atinge 500 OPG ou mais.

Os cordeiros foram abatidos com peso vivo médio de $31 \mathrm{~kg}$; posteriormente, as carcaças foram levadas para câmara de refrigeração, penduradas em ganchos apropriados pelas articulações tarso metatarsiana, com distanciamento de $17 \mathrm{~cm}$, permanecendo em temperatura de $5^{\circ} \mathrm{C}$, durante 24 horas.

Em seguida, foram registradas as medidas objetivas das carcaças (Figura 1), segundo Sañudo \& Sierra (1986) e Garcia (1998), sendo o comprimento interno da carcaça (distância máxima entre o bordo anterior da sínfese ísquio-pubiana e o bordo anterior da primeira costela, em seu ponto médio), a profundidade do tórax (distância máxima entre o esterno e o dorso da paleta), o perímetro da garupa (mensuração tomando-se como base os trocânteres dos fêmures), o comprimento externo da carcaça (distância entre a base da cauda e do pescoço), o comprimento da perna (distância entre o períneo e o bordo anterior da superfície tarso metatarsiana), a largura da garupa (largura máxima entre os trocânteres dos fêmures) e a largura do tórax (largura máxima desta região anatômica).

Posteriormente, as carcaças foram seccionadas ao meio e no lado esquerdo, foram efetuados os cortes comerciais, conforme Garcia (1998) e Silva Sobrinho(2001), podendo ser visualizados na Figura 2, a saber: paleta (obtida pela desarticulação
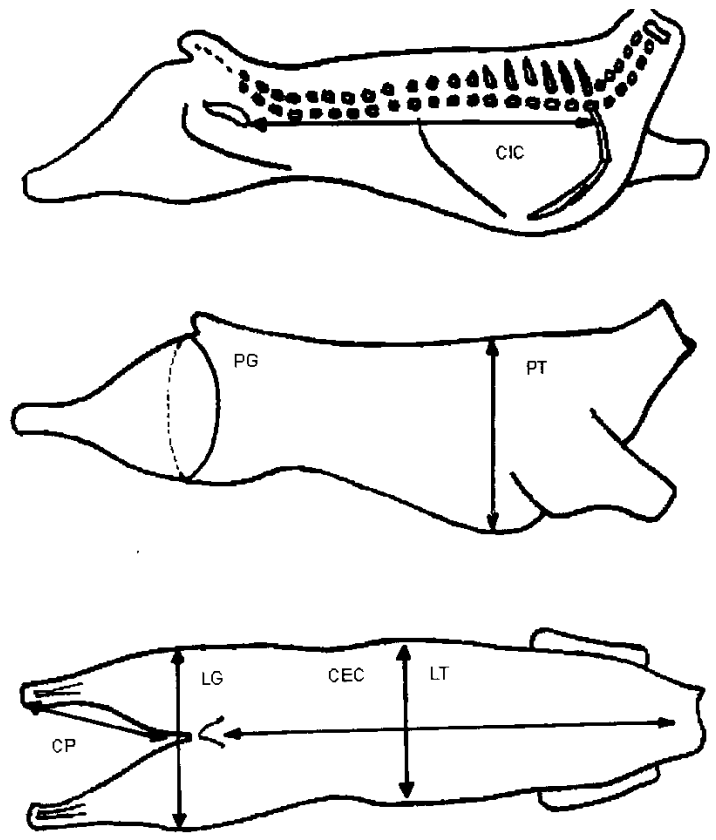

Figura 1 - Medidas objetivas das carcaças dos cordeiros alimentados com três níveis de energia na ração (2,6; 2,8 e 3,0 Mcal EM). CIC: comprimento interno da carcaça; PT: profundidade do tórax; PG: perímetro da garupa; CEC: comprimento externo da carcaça; CP: comprimento da perna; LG: largura da garupa; LT: largura do tórax.

Figure 1 - Objective measures of carcasses of lambs fed with three energy levels of ration (2.6, 2.8 and 3.0 Mcal ME). Internal carcass length, thorax depth, rump perimeter, external carcass length, leg length, rump width and thorax width.

da escápula); perna (efetua-se a secção entre a última vértebra lombar e a primeira sacra); lombo (compreende as seis vértebras lombares); costelas falsas (região localizada entre a $6^{\mathrm{a}}$ e $13^{\mathrm{a}}$ vértebras torácicas); costelas verdadeiras (possui como base óssea as cinco primeiras vértebras torácicas); baixo ou serrote (obtémse traçando um corte inicial desde o flanco à ponta do esterno, coincidindo com a articulação escápulo-umeral) e pescoço (refere-se às sete vértebras cervicais, realizando um corte oblíquo).

O perímetro do músculo Longissimus dorsi foi desenhado, para cálculo da área de olho do lombo $\left(\mathrm{cm}^{2}\right)$, entre a $12^{\mathrm{a}}$ e $13^{\mathrm{a}}$ vértebras torácicas; posteriormente realizavam-se as mensurações transversalmente no referido músculo, sendo a largura e profundidade máximas, além das espessuras mínima e má- 

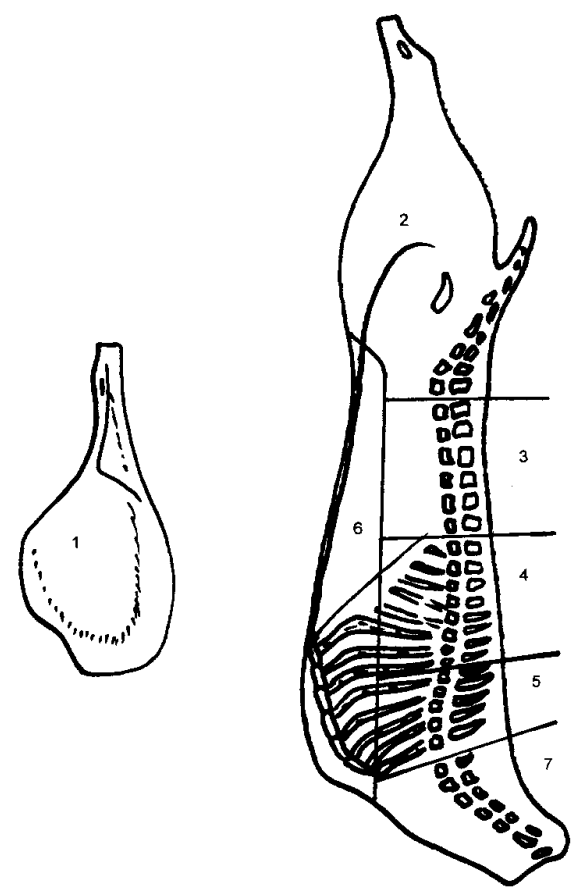

Figura 2 - Cortes efetuados na meia-carcaça esquerda dos cordeiros alimentados com três níveis de energia na ração $(2,6 ; 2,8$ e 3,0 Mcal EM). 1- paleta; 2 - perna; 3 - lombo; 4- costelas falsas; 5 - costelas verdadeiras; 6 - baixo; 7- pescoço.

Figure 2 - Cuts of left half carcass of lambs fed with three energy levels of ration (2.6, 2.8 and 3.0 Mcal ME). 1- shoulder; 2- leg; 3- loin; 4-false rib; 5-true rib; 6- breast point; 7- neck.

xima de gordura de cobertura, medidas no perfil do lombo (Figura 3).

A perna esquerda foi dissecada segundo Purchas et al. (1991). Foram determinados os pesos dos músculos que envolvem o fêmur (semimembranosus, semitendinosus, biceps femoris, quadriceps femoris, adductor) e avaliações das quantidades de gordura total, gordura intermuscular e gordura subcutânea, relação da gordura subcutânea:intermuscular, peso de ossos e comprimento do fêmur (CF), além do índice de musculosidade $(\mathrm{IM})=(\sqrt{P M / C F}) / \mathrm{CF}$, em que PM equivale o somatório do peso (g) dos cinco músculos, descritos anteriormente.

Para todos os parâmetros foi realizada a análise de variância, com modelo matemático incluindo o efeito fixo da ração (R) e com estudo das regressões polinomiais, em função dos três níveis de energia. Os cálculos foram efetuados segundo o procedimento GLM do SAS (1985).

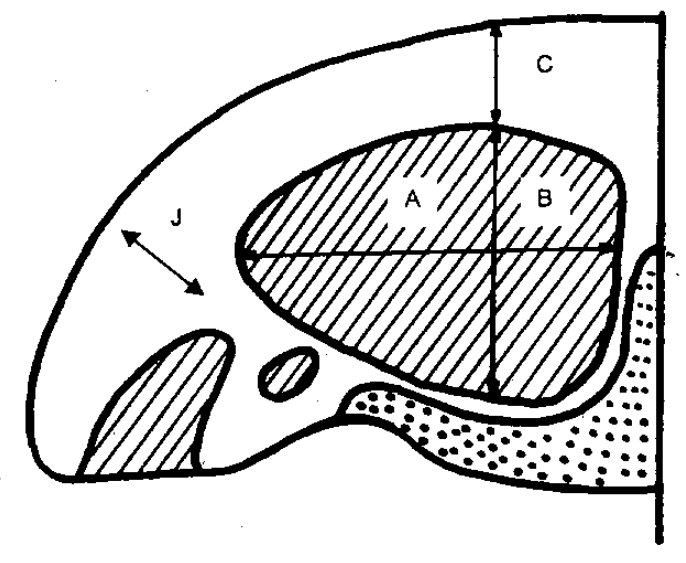

Figura 3 - Mensurações realizadas no músculo Longissimus dorsi dos cordeiros alimentados com três níveis de energia na ração $(2,6$; 2,8 e 3,0 Mcal EM). A: largura máxima; B: profundidade máxima; $C$ : espessura mínima de gordura de cobertura; e J: espessura máxima de gordura de cobertura.

Figure 3 - Measures of Longissimus dorsi muscle of lambs fed with three energy levels of ration (2.6, 2.8 and 3.0 Mcal ME). A: maximum width; B: maximum depth; $C$ : minimum fat thickness; J: maximum fat thickness.

\section{Resultados e Discussão}

$\mathrm{Na}$ Tabela 1, encontram-se os resultados das medidas objetivas das carcaças. Houve efeito significativo dos tratamentos $(\mathrm{P}<0,05)$, para a profundidade do tórax (Figura 4) e para o comprimento externo da carcaça (Figura 5). Para a profundidade do tórax ocorreu efeito linear crescente, com o melhor resultado estimado para o máximo nível de energia na dieta (3,0 Mcal EM/kg MS). Entretanto, para o comprimento externo da carcaça houve efeito inverso, ou seja, à medida que se aumentou o nível de energia, o comprimento externo da carcaça decresceu.

Os valores das medidas objetivas, de forma geral, foram próximos aos observados por Fernandes (1994) e Garcia (1998), que usaram cordeiros com sistema de terminação em confinamento; também concordando com os detectados por Macedo (1998) com ovinos em crescimento, terminados em confinamento 
Tabela 1 - Médias das medidas objetivas das carcaças $(\mathrm{cm})$ dos cordeiros alimentados com três níveis de energia e seus coeficientes de variação (CV\%)

Table 1 - Means of carcass objective measures $(\mathrm{cm})$ of lambs fed with three energy levels and its coefficients of variation (CV\%)

\begin{tabular}{|c|c|c|c|c|}
\hline \multirow[b]{2}{*}{$\begin{array}{l}\text { Variável } \\
\text { Variable }\end{array}$} & \multicolumn{4}{|c|}{$\begin{array}{c}\text { Nível de energia (Mcal EM/kg MS) } \\
\text { Energy level (Mcal ME/kg DM) }\end{array}$} \\
\hline & 2,6 & 2,8 & 3,0 & $\mathrm{CV}(\%)$ \\
\hline $\begin{array}{l}\text { Comprimento interno da carcaça } \\
\text { Internal carcass length }\end{array}$ & 49,62 & 49,50 & 49,78 & 3,86 \\
\hline $\begin{array}{l}\text { Profundidade do tórax } \\
\text { Thorax depth }\end{array}$ & $22,80^{*}$ & $23,56^{*}$ & $24,72 *$ & 7,01 \\
\hline $\begin{array}{l}\text { Perímetro da garupa } \\
\text { Rump perimeter }\end{array}$ & 61,98 & 62,19 & 61,80 & 3,14 \\
\hline $\begin{array}{l}\text { Comprimento externo da carcaça } \\
\text { External carcass length }\end{array}$ & $53,18^{*}$ & $53,28^{*}$ & $51,35^{*}$ & 3,04 \\
\hline $\begin{array}{l}\text { Comprimento da perna } \\
\text { Leg length }\end{array}$ & 32,43 & 33,76 & 32,48 & 4,43 \\
\hline $\begin{array}{l}\text { Largura da garupa } \\
\text { Rump width }\end{array}$ & 23,47 & 23,12 & 23,65 & 4,29 \\
\hline $\begin{array}{l}\text { Largura do tórax } \\
\text { Thorax width }\end{array}$ & 21,22 & 20,90 & 21,07 & 5,25 \\
\hline
\end{tabular}

* Significativo pelo teste $\mathrm{F}$ a $5 \%$ de probabilidade (Significant at $5 \%$ by $\mathrm{F}$ test).

e/ou pastejo. Todos os autores acima padronizaram o peso de abate médio de $31 \mathrm{~kg}$, com semelhança ao adotado nesta pesquisa.

Entretanto, os resultados das mensurações das carcaças foram inferiores aos observados por Garcia et al. (2000), que alimentaram cordeiros de diferentes composições genéticas (Texel x Bergamácia; Texel x Santa Inês e Santa Inês puros), porém padronizaram idade (130 dias) de abate e não peso. Ao final do experimento detectaram peso vivo de $44,80 \mathrm{~kg}$ e ao abate de $43,77 \mathrm{~kg}$. Os autores concluíram que os mestiços apresentaram superioridade em relação aos

$$
\mathrm{PT}=10,28+4,79 \times(\mathrm{R}) \quad \mathrm{R}^{2}=0,20
$$

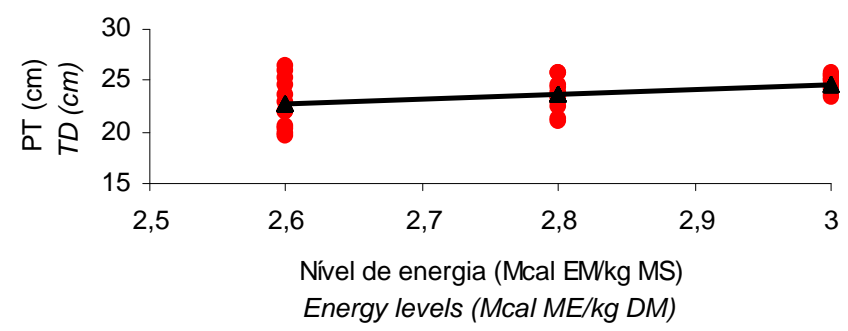

Figura 4 - Profundidade do tórax (PT) dos cordeiros $(\mathrm{cm})$, em função dos níveis de energia na ração (observado (•) e estimado (•)).

Figure 4 - Thorax depth (TD) of lambs (cm) according to energy levels in ration (observed (•) and estimated (•)).

R. Bras. Zootec., v.32, n.6, p.1380-1390, 2003
Santa Inês puro, devido a raça Texel ser especializada para carne, explorando a heterose. Dessa maneira, confirmou-se que estas características são influenciadas principalmente pelo genótipo, pois no presente estudo foi usada a raça Suffolk, específica para carne, apresentando resultados condizentes com o padrão racial, para essas medidas. Cunha et al. (2000), comparando genótipos de carne cruzados com fêmeas lanígeras, observaram que as medidas das carcaças resultantes de cruzamentos com a raça Suffolk sempre tiveram maior comprimento, seguidas pelos mestiços Ile de France.

$\mathrm{CEC}=65,44-4,58 \times(\mathrm{R}) \mathrm{R}^{2}=0,25$

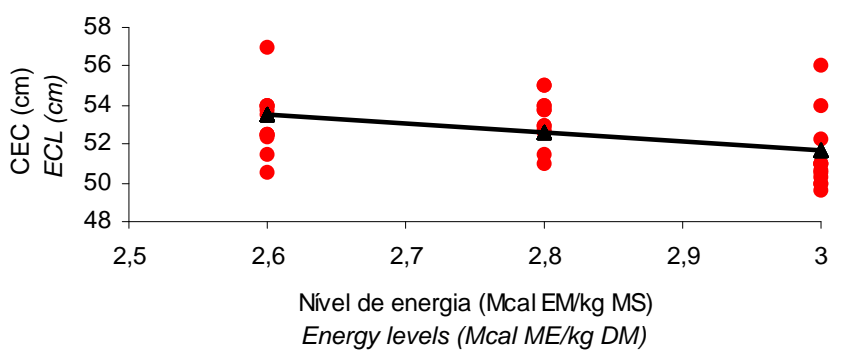

Figura 5 - Comprimento externo da carcaça (CEC) dos cordeiros $(\mathrm{cm})$, em função dos níveis de energia na ração (observado (•) e estimado $(\bullet)$ ).

Figure 5 - External carcass length (ECL) of lambs $(\mathrm{cm})$ according to energy levels in ration (observed (•) and estimated (•)). 
Nas Tabelas 2 e 3, estão descritos os resultados dos pesos e rendimentos dos cortes. Constatou-se efeito significativo $(\mathrm{P}<0,05)$ para o peso (Figura 6) e rendimento das costelas verdadeiras (Figura 7). Para ambos parâmetros ocorreu efeito linear crescente, conforme aumentou-se o nível de energia para os cordeiros, concomitantemente melhoraram os resultados estimados, com valores superiores para fornecimento de 3,0 Mcal EM/kg MS na ração.
Os pesos dos cortes no presente estudo são superiores aos verificados por Osório (1992), Fernandes (1994) e Garcia (1998), que usaram a mesma metodologia, para cordeiros confinados na fase de pós desmama, obtendo os seguintes resultados: perna 1,69; 1,98 e $1,95 \mathrm{~kg}$; paleta 1,$07 ; 1,14$ e 1,16 kg, o lombo 0,61 ; 0,59 e $0,70 \mathrm{~kg}$; as costelas falsas 0,$55 ; 0,57$ e $0,66 \mathrm{~kg}$; e as costelas verdadeiras 0,$40 ; 0,37$ e $0,37 \mathrm{~kg}$, respectivamente. Estes valores confirmam a boa qualidade

Tabela 2 - Médias dos pesos dos cortes $(\mathrm{kg})$ dos cordeiros alimentados com três níveis de energia e seus coeficientes de variação (CV\%)

Table 2 - Means of weights of cuts $(\mathrm{kg})$ of lambs fed with three energy levels and its coefficients of variation (CV\%)

\begin{tabular}{|c|c|c|c|c|}
\hline \multirow[b]{2}{*}{$\begin{array}{l}\text { Variável } \\
\text { Variable } \\
\end{array}$} & \multicolumn{4}{|c|}{$\begin{array}{l}\text { Nível de energia (Mcal EM/kg MS) } \\
\text { Energy level (Mcal ME/kg DM) }\end{array}$} \\
\hline & 2,6 & 2,8 & 3,0 & $\mathrm{CV}(\%)$ \\
\hline $\begin{array}{l}\text { Paleta } \\
\text { Shoulder }\end{array}$ & 1,46 & 1,51 & 1,45 & 6,09 \\
\hline $\begin{array}{l}\text { Perna } \\
\text { Leg }\end{array}$ & 2,60 & 2,54 & 2,58 & 5,74 \\
\hline $\begin{array}{l}\text { Lombo } \\
\text { Loin }\end{array}$ & 0,77 & 0,78 & 0,79 & 11,71 \\
\hline $\begin{array}{l}\text { Costelas falsas } \\
\text { False ribs }\end{array}$ & 0,73 & 0,77 & 0,78 & 11,12 \\
\hline $\begin{array}{l}\text { Costelas verdadeiras } \\
\text { True ribs }\end{array}$ & $0,44^{*}$ & $0,49^{*}$ & $0,50 *$ & 12,55 \\
\hline $\begin{array}{l}\text { Baixo } \\
\text { Breast point }\end{array}$ & 0,67 & 0,67 & 0,70 & 12,32 \\
\hline $\begin{array}{l}\text { Pescoço } \\
\text { Neck }\end{array}$ & 0,62 & 0,65 & 0,65 & 15,99 \\
\hline
\end{tabular}

* Significativo pelo teste $\mathrm{F}$ a $5 \%$ de probabilidade (Significant at $5 \%$ by $\mathrm{F}$ test).

Tabela 3 - Médias dos rendimentos dos cortes (\%) dos cordeiros alimentados com três níveis de energia e seus coeficientes de variação (CV\%)

Table 3 - Means of yield of cuts (\%) of lambs fed with three energy levels and its coefficients of variation (CV\%)

\begin{tabular}{|c|c|c|c|c|}
\hline \multirow[b]{2}{*}{$\begin{array}{l}\text { Variável } \\
\text { Variable }\end{array}$} & \multicolumn{4}{|c|}{$\begin{array}{c}\text { Nível de energia (Mcal EM/kg MS) } \\
\text { Energy level (Mcal ME/kg DM) }\end{array}$} \\
\hline & 2,6 & 2,8 & 3,0 & $\mathrm{CV}(\%)$ \\
\hline $\begin{array}{l}\text { Paleta } \\
\text { Shoulder }\end{array}$ & 20,09 & 20,38 & 19,47 & 5,77 \\
\hline $\begin{array}{l}\text { Perna } \\
\text { Leg }\end{array}$ & 35,71 & 34,39 & 34,64 & 5,10 \\
\hline $\begin{array}{l}\text { Lombo } \\
\text { Loin }\end{array}$ & 10,52 & 10,47 & 10,52 & 8,94 \\
\hline $\begin{array}{l}\text { Costelas falsas } \\
\text { False ribs }\end{array}$ & 9,95 & 10,37 & 10,40 & 8,41 \\
\hline $\begin{array}{l}\text { Costelas verdadeiras } \\
\text { True ribs }\end{array}$ & $6,00 *$ & $6,61^{*}$ & $6,70^{*}$ & 11,17 \\
\hline $\begin{array}{l}\text { Baixo } \\
\text { Breast point }\end{array}$ & 9,15 & 9,08 & 9,40 & 9,26 \\
\hline $\begin{array}{l}\text { Pescoço } \\
\text { Neck }\end{array}$ & 8,47 & 8,70 & 8,75 & 12,90 \\
\hline
\end{tabular}

* Significativo pelo teste $\mathrm{F}$ a $5 \%$ de probabilidade (Significant at $5 \%$ by $\mathrm{F}$ test).

R. Bras. Zootec., v.32, n.6, p.1380-1390, 2003 
das carcaças de cordeiros terminados em creep feeding, pois no presente experimento os pesos destes cortes comerciais foram superiores, mesmo sendo preestabelecido o peso vivo de abate, tendo ainda como vantagem a menor idade de abate.

Os dados dos rendimentos dos cortes, obtidos a partir do peso dos mesmos, em relação à meia carcaça, apresentaram similaridade aos observados por Fernandes (1994) e Garcia (1998) que usaram cordeiros confinados; e Macedo (1998) que estudou tais parâmetros para cordeiros terminados em confinamento e/ou pastejo, verificando os seguintes resultados: paleta 19,$3 ; 19,5$ e $19,5 \%$, perna 33,$7 ; 33,0$ e $33,6 \%$, lombo 10,2; 11,7 e 9,6\%, costelas falsas 9,7 ; 11,0 e $9,4 \%$, costelas verdadeiras 6,$3 ; 6,2$ e $11,5 \%$, baixo 12,$3 ; 9,4$ e $11,4 \%$ e pescoço 8,0; 9,4 e 11,4\%, respectivamente. Entretanto, os pesos e rendimentos dos cortes que revelaram maior variação foram o baixo e as costelas verdadeiras, concordando com Osório (1992).

Os rendimentos da perna e da paleta foram superiores aos observados por Pereira \& Santos (2001), que usaram cordeiros Suffolk criados em creep feeding, porém confinados por um curto período, obtendo rendimentos de 25,4 e 12,6\%, respectivamente. Entretanto, adotaram peso de abate superior e conseqüentemente os cordeiros apresentaram idade mais avançada, quando comparados aos obtidos no presente experimento; confirmando que existe uma tendência desses dois cortes apresentarem o peso reduzido com o avanço da idade, devido aos seus ritmos de crescimento rápido (Sousa, 1993).

$C V=0,035+0,16 x(R) \quad R^{2}=0,19$

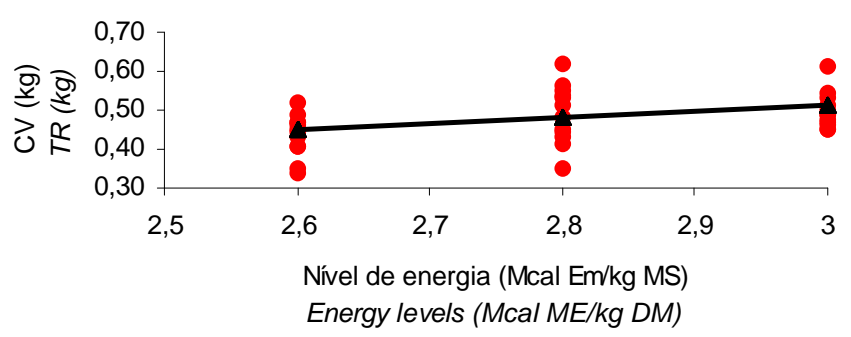

Figura 6 - Peso $(\mathrm{kg})$ das costelas verdadeiras (CV) dos cordeiros, em função dos níveis de energia na ração (observado $(\bullet)$ e estimado $(\bullet)$ ).

Figure 6 - Weight $(\mathrm{kg})$ true ribs (TR) of lambs according to energy levels in ration (observed $(\bullet)$ and estimated $(\bullet))$.
Os resultados dos pesos e das percentagens dos cortes foram próximos aos valores encontrados por Monteiro et al. (1999), que utilizaram níveis crescentes de polpa cítrica, nas dietas de cordeiros confinados. Estes parâmetros não têm grande variação, quando se abatem animais de raças específicas para carne ou produtos de cruzamento industrial, com pesos próximos, sendo criados num sistema intensivo de produção, seja em confinamento ou creepfeeding.

Na Tabela 4 encontram-se as mensurações realizadas no músculo Longissimus dorsi, não ocorrendo efeito dos tratamentos $(\mathrm{P}>0,05)$ para os parâmetros avaliados. A área de olho de lombo é uma medida objetiva de grande valor na predição da quantidade de músculo na carcaça (Macedo, 1998), enquanto a avaliação da gordura é fundamental, sendo fator determinante de sua qualidade (McClure et al., 1994).

A área do olho de lombo foi superior à obtida por Macedo (1998), que trabalhou com cordeiros Corriedale e mestiços Bergamácia x Corriedale e Hampshire Down x Corriedale, adotando a terminação em pastejo e confinamento, ambas as dietas com $18 \%$ PB e 2,82 Mcal EM, que obteve valores de 9,03 e $10,21 \mathrm{~cm} 2$, respectivamente. Desta maneira, confirma-se valor desejável desta mensuração para os cordeiros do presente experimento, com média de $12,62 \mathrm{~cm} 2$. A área de olho de lombo desses animais foi aproximadamente $28 \%$ superior em relação aos cordeiros em pastejo e 19\% aos confinados, quando comparados aos obtidos pelo autor citado anteriormente. Também superior aos detectados por Siqueira $\&$ Fernandes (2000), que usaram cordeiros desma-

$C V=1,54+1,75 x(R) \quad R^{2}=0,17$

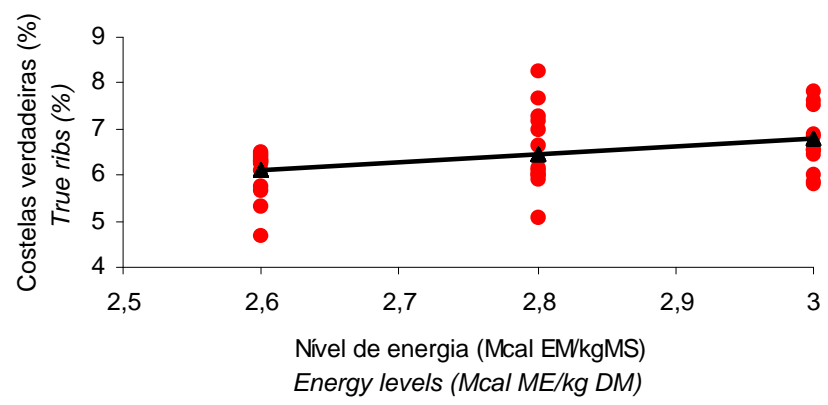

Figura 7 - Rendimento (\%) das costelas verdadeiras (CV) dos cordeiros, em função dos níveis de energia na ração (observado (•) e estimado $(\bullet))$.

Figure 7 - Yield (\%) of true ribs of lambs according to energy levels in ration (observed $(\bullet)$ and estimated $(\bullet)$ ). 
Tabela 4 - Médias das mensurações do músculo Longissimus dorsi (cm) dos cordeiros alimentados com três níveis de energia e seus coeficientes de variação (CV\%)

Table 4 - Means of measures of muscle Longissimus dorsi $(\mathrm{cm})$ of lambs fed with three energy levels and coefficients of variation (CV\%)

\begin{tabular}{|c|c|c|c|c|}
\hline \multirow[b]{2}{*}{$\begin{array}{l}\text { Variável } \\
\text { Variable }\end{array}$} & \multicolumn{4}{|c|}{$\begin{array}{l}\text { Nível de energia (Mcal EM/kg MS) } \\
\text { Energy level (Mcal ME/kg DM) }\end{array}$} \\
\hline & 2,6 & 2,8 & 3,0 & $\mathrm{CV}(\%)$ \\
\hline $\begin{array}{l}\text { A (largura máxima) } \\
\text { A (maximum width) }\end{array}$ & 5,32 & 5,34 & 5,35 & 5,06 \\
\hline $\begin{array}{l}\mathrm{B} \text { (profundidade máxima) } \\
B \text { (maximum depth) }\end{array}$ & 2,86 & 3,05 & 3,05 & 8,24 \\
\hline $\begin{array}{l}\mathrm{C} \text { (espessura mínima de gordura) } \\
\mathrm{C} \text { (minimum fat thickness) }\end{array}$ & 0,16 & 0,18 & 0,21 & 33,67 \\
\hline $\begin{array}{l}\text { J (espessura máxima de gordura) } \\
\text { J (maximum fat thickness) }\end{array}$ & 0,35 & 0,35 & 0,35 & 31,67 \\
\hline $\begin{array}{l}\text { Área de olho de lombo }\left(\mathrm{cm}^{2}\right) \\
\text { Loin eye area }\left(\mathrm{cm}^{2}\right)\end{array}$ & 12,57 & 12,36 & 12,93 & 10,15 \\
\hline
\end{tabular}

mados aos 60 dias e terminados em confinamento (15\% PB e 2,72 Mcal EM), sendo puros Corriedale e suas cruzas com Ile de France, com a área de olho de lombo 8,51 e 9,44 cm2, largura máxima do lombo 5,10 e $5,36 \mathrm{~cm}$, profundidade máxima 2,41 e $2,49 \mathrm{~cm}$, espessura mínima de gordura de cobertura 0,14 e 0,15 $\mathrm{cm}$ e espessura máxima de gordura de cobertura 0,33 e $0,32 \mathrm{~cm}$, respectivamente. Portanto, os resultados demonstram o benefício da boa nutrição na fase de lactente, com fornecimento da ração em creep feeding.

As medidas do músculo Longissimus dorsi estão próximas às obtidas por Neres et al. (2001b) que adotaram peso de abate de $28 \mathrm{~kg}$ para cordeiros Suffolk criados em creep feeding e terminados em confinamento, sendo a área de olho de lombo $11,19 \mathrm{~cm}^{2}$, largura máxima do lombo $5,56 \mathrm{~cm}$, profundidade máxima $2,90 \mathrm{~cm}$ e espessura máxima de gordura de cobertura $0,40 \mathrm{~cm}$. A área de olho de lombo $\left(11,19 \mathrm{~cm}^{2}\right)$ inferior à obtida no presente estudo $\left(12,62 \mathrm{~cm}^{2}\right)$, confirma a maturação tardia do músculo Longissimus dorsi, pois os cordeiros do presente estudo foram abatidos com peso superior (31,0 kg). Cunha et al. (2000) encontraram correlação positiva $(\mathrm{r}=0,87)$ da área de olho de lombo com o peso de abate de ovinos, mostrando que este parâmetro, e não o genótipo, é fator limitante dessa variável.

Na Tabela 5, observam-se os resultados da avaliação da composição tecidual e da musculosidade da perna de cordeiros alimentados com três níveis de energia na ração. A análise de variância indicou efeito significativo $(\mathrm{P}<0,05)$ dos níveis de energia na ração, apenas para a gordura intermuscular (Figura 8), ocorrendo efeito quadrático, com valor mínimo estimado para o nível 2,74 Mcal EM/kg MS e quantidade superior de gordura intermuscular para o nível de 3,0 Mcal EM/kg MS.

Ruiz de Huidobro \& Cañeque (1994), trabalhando na Espanha com a raça Manchega, obtiveram 105,75 g de gordura intermuscular na perna de cordeiros abatidos aos $35 \mathrm{~kg}$ de peso vivo. A média geral para esse experimento foi de $88,27 \mathrm{~g}$; para a dieta com maior nível de energia (3,0 Mcal EM), o peso de gordura intermuscular $(115,0 \mathrm{~g})$ ficou próximo aos dados citados pelos autores descritos anteriormente. Silva Sobrinho (1999), estudando a composição tecidual da perna de cordeiros das raças Romney, Finn-Texel e Finn-Dorset, registrou valores de 141, 134 e $137 \mathrm{~g}$, respectivamente, em cordeiros abatidos com 41,4 kg de peso vivo.

Preziuso et al. (1999) avaliaram três dietas para cordeiros Appenine, com diferentes fontes de energia na dieta. A dieta 1 continha $9 \%$ de cevada floculada, na dieta 2 adicionaram-se $5 \%$ de óleo de milho e ambos os lotes receberam feno de alfafa à vontade. A dieta 3 tinha a mesma composição percentual da 2, porém sem o feno. Depois de efetuada a dissecção da perna, verificaram efeito significativo para a gordura subcutânea, para os cordeiros que receberam a dieta 3 , com valores de 8,$55 ; 8,26$ e $11,44 \%$, respectivamente, para as três dietas. Entretanto apresentaram similaridade para gordura intermuscular. No presente trabalho, os valores de gordura subcutânea não diferiram entre si $(180,83 ; 164,0$ e 188,33 g), estando porém próximos aos valores citados na literatura. Entretanto, verificou-se tendência em aumento desta caracte- 
rística no presente estudo, à medida que se elevou a concentração de energia na ração.

Quanto à relação dos pesos das gorduras subcutânea:intermuscular, a Tabela 5 indica que os valores obtidos $(2,32 ; 2,58 ; 1,82)$ são superiores aos observados por Silva Sobrinho (1999), que encontrou como média para os três grupos genéticos de ovinos de carne valor igual a 1,37. De acordo com Ruiz de Huidobro \& Cañeque (1994), alta relação gordura subcutânea: intermuscular pode indicar produto desejável para o mercado, uma vez que a gordura subcutânea garante a boa conservação da carcaça no frigorífico. Isso demonstra que, apesar de os cordeiros do presente trabalho terem sido abatidos
$\mathrm{GIP}=5.497,5-3.962,91 \times(\mathrm{R})+722,91 \times(\mathrm{R})^{2}$ $R^{2}=0,41$

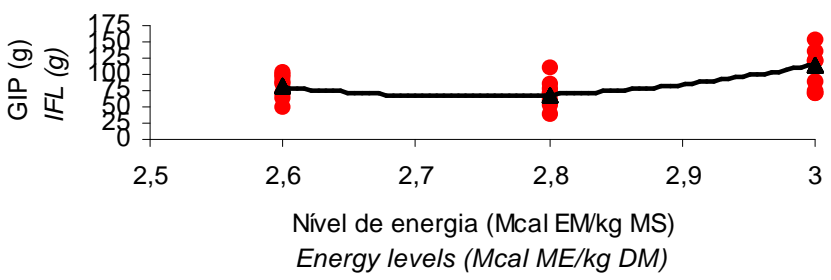

Figura 8 - Gordura intermuscular (g) da perna (GIP) dos cordeiros, em função dos níveis de energia na ração (observado $(\bullet)$ e estimado $(\bullet)$ ).

Figure 8 - Intermuscular fat (g) of leg (IFL) of lambs according to energy levels in ration (observed (๑) and estimated (•)).

Tabela 5 - Médias da composição tecidual $(\mathrm{g})$ da perna dos cordeiros alimentados com três níveis de energia e seus coeficientes de variação (CV\%)

Table 5 - Means of leg tissue composition (cm) of lambs fed with three energy levels and its coefficients of variation (CV\%)

\begin{tabular}{|c|c|c|c|c|}
\hline \multirow[b]{2}{*}{$\begin{array}{l}\text { Variável } \\
\text { Variable }\end{array}$} & \multicolumn{4}{|c|}{$\begin{array}{l}\text { Nível de energia (Mcal EM/kg MS) } \\
\text { Energy level (Mcal ME/kg DM) }\end{array}$} \\
\hline & 2,6 & 2,8 & 3,0 & $\mathrm{CV}(\%)$ \\
\hline \multicolumn{5}{|l|}{$\begin{array}{l}\text { Músculo (g) } \\
\text { Muscle }\end{array}$} \\
\hline $\begin{array}{l}\text { Músculo total } \\
\text { Total muscle }\end{array}$ & $1.511,67$ & $1.495,00$ & $1.575,83$ & 6,18 \\
\hline $\begin{array}{l}\text { Biceps femoris } \\
\text { Semitendinosus } \\
\text { Quadriceps femoris } \\
\text { Adductor } \\
\text { Semimembranosus }\end{array}$ & $\begin{array}{c}225,00 \\
65,00 \\
305,00 \\
95,83 \\
212,50\end{array}$ & $\begin{array}{l}226,17 \\
68,50 \\
265,67 \\
103,50 \\
218,50\end{array}$ & $\begin{array}{c}224,17 \\
74,17 \\
282,50 \\
95,83 \\
217,50\end{array}$ & $\begin{array}{c}5,38 \\
17,13 \\
11,16 \\
14,68 \\
8,85\end{array}$ \\
\hline \multicolumn{5}{|l|}{ Gordura $(\mathrm{g})$} \\
\hline $\begin{array}{l}\text { Fat }(g) \\
\text { Gordura total } \\
\text { Total fat }\end{array}$ & 261,67 & 233,00 & 303,33 & 21,59 \\
\hline $\begin{array}{l}\text { Gordura subcutânea } \\
\text { Subcutaneous fat }\end{array}$ & 180,83 & 164,00 & 188,33 & 30,03 \\
\hline $\begin{array}{l}\text { Gordura intermuscular } \\
\text { Intermuscular fat }\end{array}$ & 80,83 & 69,00 & 115,00 & 29,26 \\
\hline $\begin{array}{l}\text { Relação músculo:osso } \\
\text { Muscle:bone ratio }\end{array}$ & 5,64 & 5,72 & 5,69 & 8,97 \\
\hline $\begin{array}{l}\text { Relação SC:IM* } \\
\text { Ratio SB:IM* }\end{array}$ & 2,32 & 2,58 & 1,82 & 42,62 \\
\hline $\begin{array}{l}\text { Índice de musculosidade** } \\
\text { Muscularity index** }\end{array}$ & 0,42 & 0,44 & 0,46 & 7,75 \\
\hline \multicolumn{5}{|l|}{ Ossos } \\
\hline $\begin{array}{l}\text { Peso dos ossos }(\mathrm{g}) \\
\text { Bone weight }(g)\end{array}$ & 485,83 & 439,67 & 463,33 & 12,52 \\
\hline $\begin{array}{l}\text { Comprimento do fêmur }(\mathrm{cm}) \\
\text { Femur length }(\mathrm{cm})\end{array}$ & 17,23 & 16,48 & 16,17 & 5,02 \\
\hline
\end{tabular}

* Relação do peso da gordura subcutânea:gordura intermuscular; **índice de musculosidade $=(\sqrt{P M / C F}) / C F$, em que PM equivale a somatória do peso $(\mathrm{g})$ dos 5 músculos Biceps femoris+Semitendinosus+Quadriceps femoris+Adductor+Semimembranosus (Purchas et al., 1991). CF: comprimento do fêmur.

* Ratio of subcutaneous fat weight to intermuscular fat weight; ${ }^{* *}$ Muscularity index $=(\sqrt{M W / F C}) / F C$, which MW is the weight of five muscles Biceps femoris+Semitendinosus+Quadriceps femoris+Addutor+Semimembranosus(Purchas et al., 1991). FC: femur length. 
com a idade média igual a 63 dias, os mesmos apresentam cobertura de gordura favorável na carcaça.

Com relação às demais características avaliadas (Tabela 5), os valores encontram-se dentro dos descritos na literatura (Preziuso et al., 1999; Oliveira et al., 1998). Purchas et al. (1991) afirmaram que avaliação da musculosidade da carcaça baseia-se na profundidade dos músculos que circundam o fêmur, em relação ao comprimento do mesmo. Esse índice pode estar relacionado à escores subjetivos de conformação e à relação músculo:osso, tradicionalmente avaliados, porém nem sempre apresentam paralelismo. Em carcaças de diferentes grupos genéticos de ovinos de carne, Silva Sobrinho (1999) obteve valor médio de musculosidade igual a 0,45 , similar ao encontrado no presente trabalho.

\section{Conclusões}

O nível ótimo de energia que proporcionou os melhores resultados para as medidas objetivas, pesos e rendimentos dos cortes comerciais, composição tecidual e musculosidade da carcaça dos cordeiros foi de 3,0 Mcal EM/kg MS na ração.

O creep feeding pode ser considerado técnica indicada para a terminação de ovinos Suffolk, mantendo as boas características da carcaça dos cordeiros.

\section{Literatura Citada}

BARROS, N.N.; SIMPLÍCIO, A.A. Produção intensiva de ovinos de corte: perspectivas e cruzamentos. In: SIMPÓSIO MINEIRO DE OVINOCULTURA, 1., 2001. Anais...Lavras: Universidade Federal de Lavras, p.21-49. 2001.

CUNHA, E.A.; SANTOS, L.E.; BUENO, M.S. et al. Utilização de carneiros de raças de corte para obtenção de cordeiros precoces para abate em plantéis produtores de lã. Revista Brasileira de Zootecnia, v.29, n.1, p.243-252, 2000.

EL KARIN, A.I.A.; OWEN, J.B.; WHITAKER, C.J. Measurement on slaughter weight, side weight, carcass joints and their association with carcass composition of two types of Sudan Desert sheep. Journal of Agricultural Science, v.110, n.1, p.65-69, 1988.

FERNANDES, S. Peso vivo ao abate e características de carcaça de cordeiros da raça Corriedale e mestiços Ile de France $X$ Corriedale recriados em confinamento. Botucatu: Universidade Estadual Paulista, 1994. 82p. Dissertação (Mestrado em Zootecnia) - Universidade Estadual Paulista, 1994.

GARCIA, I.F.F.; PEREZ, J.R.O.; OLIVEIRA, M.V. Características de carcaça de cordeiros Texel x Bergamácia, Texel x Santa Inês e Santa Inês Puros, terminados em confinamento, com casca de café como parte da dieta. Revista Brasileira de Zootecnia, v.30, n.3, p.253-260, 2000.
GARCIA, C.A.; MONTEIRO, A.L.G.; COSTA, C. Produção de cordeiros Suffolk criados e terminados em creep feeding. O Berro, n.46, p.35-42, 2001.

GARCIA, C.A. Avaliação do resíduo de panificação "biscoito" na alimentação de ovinos e nas características quantitativas e qualitativas da carcaça. Jaboticabal: Universidade Estadual Paulista, 1998. 79p. Dissertação (Mestrado em Zootecnia) - Universidade Estadual Paulista, 1998.

HUIDOBRO, F.R., CAÑEQUE, V. Produccion de carne en corderos de raza Manchega. III. Composição tisular de las canales y de las piezas. Revista Producción Sanidad Animal, v.9, n.1, p.57-69, 1994.

MACEDO, F.A. Recria e terminação de cordeiros confinados. In: SIMPÓSIO PAULISTA DE OVINOCULTURA, 4., 1995, Campinas. Anais... Campinas: FUNEP, 1995. p.50-57.

MACEDO, F.A.F. Desempenho e características de carcaças de cordeiros Corriedale e mestiços Bergamácia x Corriedale e Hampshire Down x Corriedale, terminados em confinamento. Botucatu: Universidade Estadual Paulista, 1998. 72p. Tese (Doutorado em Zootecnia) - Universidade Estadual Paulista, 1998.

MATOS, M.S.; MATOS, P.F. Laboratório clínico médico veterinário. 2.ed. Rio de Janeiro: Atheneu, 1988. 238p.

McCLURE, K.E.; VANKEUREN, R.W.; ALTHOPUSE,P.G. Performance and carcass characteristics of weaned lambs either grazed on orchardgrass, ryegrass or alfalfa or fed allconcentrate diets in drylot. Journal of Animal Science, v.72, p.3230-3237, 1994.

MONTEIRO, A.L.G.; NERES, M.A.; GARCIA, C.A. et al. 2000. Avaliação da compacidade e da composição tecidual das carcaças de cordeiros alimentados em creep feeding. In: REUNIÃO ANUAL DA SOCIEDADE BRASILEIRA DE ZOOTECNIA, 37, 2000, Viçosa. Anais...Viçosa: Sociedade Brasileira de Zootecnia/ CD ROM.

MONTEIRO, A.L.G.; GARCIA, C.A.; NERES, M.A. et al. Pesos e rendimentos dos cortes e órgãos de cordeiros confinados alimentados com polpa cítrica. Revista Unimar Ciências, v.8, n.1, p.97-100, 1999.

NATIONAL RESEARCH COUNCIL - NRC. Nutrient requirements of sheep. Washington, D.C.: National Academy Press, 1985. 99p.

NERES, M.A.; GARCIA, C.A.; MONTEIRO, A.L.G. et al. Níveis de feno de alfafa e forma física da ração no desempenho de cordeiros em creep feeding. Revista Brasileira de Zootecnia, v.30, n.3, p.941-947, 2001a.

NERES, M.A.; MONTEIRO, A.L.G.; GARCIA, C.A. et al. Forma física da ração e pesos de abate nas características de carcaça de cordeiros em creep feeding. Revista Brasileira de Zootecnia, v.30, n3, p.948-954, 2001 b.

OLIVEIRA, N.M.; OSÓRIO, J.C.S.; MONTEIRO, E.M. Produção de carne em ovinos de cinco genótipos.4. Composição regional e tecidual. Revista Ciência Rural, v.28, n.1, p.125-129, 1998.

OSÓRIO, J.C.S. Estudio de la calidad de canales comercializadas en el tipo ternasco según la procedencia: bases para la mejora de dicha calidad en Brasil. Zaragoza, 1992. 335p. Tesis (Doctoral) - Facultad de Veterinaria, Universidad de Zaragoza.

PEREIRA, J.R.A.; SANTOS, I.C. Sistema intensivo para produção de carne ovina. In: PEREIRA, J.R.A.; SANTOS, I.C.; VENANCIO, W.S. Produção de ovinos. Ponta Grossa: Universidade Estadual de Ponta Grossa, 2001. p.7-19. 
PREZIUSO, G.; RUSSO, C.; CASAROSA, L et al. Effect of diet energy source on weight gain and carcass characteristics of lambs. Small Ruminant Research, v.33, p.9-15, 1999.

PURCHAS, R.W.; DAVIES, A.S.;ABDULLAH,A.Y. An objective measure of muscularity: changes with animal growth and differences between genetic lines of Southdown sheep. Meat Science, v.30, p.81-94, 1991.

SÃNUDO, C.; SIERRA, I.; OLLETA, J.L. et al. Influence of weaning on carcass quality, fatty acid composition and meat quality in intensive lamb production systems. Animal Science, v.66, p.175-187, 1988.

SAÑUDO, C., SIERRA, I. Calidad de la canal en la especie ovina. Revista Ovis, v.1, p. 127-53. 1986.

STATISTICAL ANALYSIS SYSTEM - SAS. User's guide: Statistics. 5.ed. Cary: 1985. 955p.

SILVA SOBRINHO, A.G. Aspectos quantitativos e qualitativos da produção de carne ovina. In: Produção animal na visão dos Brasileiros. REUNIÃO ANUAL DA SOCIEDADE BRASILEIRA DE ZOOTECNIA, 38., 2001, Piracicaba. Anais...Piracicaba: Sociedade Brasileira de Zootecnia, 2001. p.425-446.

SILVA SOBRINHO, A.G. Body composition and characteristics of carcasses from lambs of different genotypes and ages at slaughter. Palmerston North, NZ: Massey University, 1999. 61p. Post Doctoral research report. Massey University, 1999.
SIQUEIRA, E.R.; SIMÕES, C.D.; FERNADES, S. Efeito do sexo e do peso ao abate sobre a produção de carne de cordeiro 1. Velocidade de crescimento, caracteres quantitativos da carcaça, pH da carne e resultado econômico. Revista Brasileira de Zootecnia, v.30, n.3, p.844-848, 2001.

SIQUEIRA, E.R.; FERNADES, S. Efeito do genótipo sobre as medidas objetivas e subjetivas da carcaça de cordeiros terminados em confinamento. Revista Brasileira de Zootecnia, v.29, n.1, p.306-311, 2000.

SOUSA, O.C.R. Rendimento de carcaça, composição regional e física da paleta e quarto em cordeiros Romney Marsh abatidos aos 90 e 180 dias de idade. Pelotas: Universidade Federal de Pelotas, 1993. 102p. Dissertação (Mestrado em Zootecnia) - Universidade Federal de Pelotas, 1993.

Recebido em: 28/05/02

Aceito em: 24/03/03 